\title{
RING AUTOSOMES: SOME UNEXPECTED FINDINGS
}

\author{
Caba L ${ }^{1, *}$, Rusu $\mathrm{C}^{1,2}$, Plăiaşu V ${ }^{3}$, Gug $\mathrm{G}^{4,5}$, Grămescu $\mathrm{M}^{1}$, Bujoran $\mathrm{C}^{2}$, \\ Ochiană $\mathrm{D}^{3}$, Voloşciuc $\mathrm{M}^{2}$, Popescu $\mathrm{R}^{1}$, Braha $\mathrm{E}^{1,2}$, Pânzaru $\mathrm{M}^{1,2}$, \\ Butnariu L ${ }^{1,2}$, Sireteanu $\mathrm{A}^{1}$, Covic $\mathrm{M}^{1}$, Gorduza EV ${ }^{1}$
}

*Corresponding Author: Dr. Lavinia Caba, "Grigore T. Popa" University of Medicine and Pharmacy Iasi, Department
of Medical Genetics, 16 Universitatii str., Iasi, 700115, Romania; Tel.: +40724962671; Email: lavinia zanet@yahoo.com

\begin{abstract}
Ring chromosomes are rare entities, usually associated with phenotypic abnormalities in correlation with the loss of genetic material. There are various breakpoints and sometimes there is a dynamic mosaicism that is reflected in clinical features. Most of the ring chromosomes are de novo occurrences. Our study reflects the experience of three Romanian cytogenetic laboratories in the field of ring chromosomes. We present six cases with ring chromosomes involving chromosomes 5, 13, 18, and 21. All ring chromosomes were identified after birth in children with plurimalformative syndromes. The ring chromosome was present in mosaic form in three cases, and this feature reflects the ring's instability. In case of ring chromosome 5 , we report a possible association with oculo-auriculo-vertebral spectrum.
\end{abstract}

Keywords: Chromosomal instability; Variable phenotype; Mosaicism; Rare disease; Ring chromosome

\section{INTRODUCTION}

Ring chromosomes are rare chromosomal abnormalities with an overall frequency of $1 / 30,000$ -

\footnotetext{
1 "Grigore T. Popa" University of Medicine and Pharmacy Iasi, Department of Medical Genetics, Iasi, Romania

2 "Sf. Maria" Pediatric Hospital Iasi, Department of Medical Genetics, Iasi, Romania

3 "Prof. dr. Alfred Rusescu" Institute for Mother and Child Care Bucharest, Department of Medical Genetics, Bucharest, Romania

4 "Victor Babeş" University of Medicine and Pharmacy Timisoara, Department of Medical Genetics, Timisoara, Romania

5 "Dr. Cristina Gug" Cytogenetic Laboratory, Timisoara, Romania
}

$1 / 60,000$ [1]. They are described for all human chromosomes and almost $50.0 \%$ of ring autosomes originated from acrocentric chromosomes [2].

In the majority of cases, the chromosomal abnormality is de novo and is formed during meiosis or early post zygotic divisions [3-5]. There are different formation mechanisms, the most frequent being breakage in both arms and fusion of the ends of the resulting centromeric fragment (these ends become sticky), with loss of terminal fragments. Another mechanism, demonstrated using high resolution molecular techniques, involves a telomere-to-telo-mere fusion that generates a pseudo-complete ring chromosome, associated with a small loss of genetic material responsible for cryptic deletions in the majority of cases [6-8]. The last mechanism described implies duplication with inversion associated with a terminal deletion $[9,10]$.

Only $1.0 \%$ of all ring chromosomes are inherited, with demonstrated maternal origin in $90.0 \%$ of cases, while in men, the presence of a ring chromosome blocks spermatogenesis and induces infertility. Up to the present time, the reported inherited rings are derivatives of chromosomes $11,14,15,17,18$, 20, 21 and 22 [11].

The ring chromosome can be detected in homogenous or mosaic form. In the first case, the anomaly originated in parental meiosis or in the early stages of embryogenesis. The mosaic abnormality can be explained by a mitotic non disjunction associated with ring instability. Some arguments for post zygotic origin of the anomaly was the detection of a line with monosomy in the case of small chromosomes (ring/ monosomy mosaicism) and the presence of a diploid normal line in the case of chromosomes rich in euchromatin (ring/normal line mosaicism) $[3,4,12]$. 
The presence of a ring chromosome induces a pheno-typic variability correlated with the size of lost genetic material and mitotic instability [9]. The severity of the phenotype depends on factors such as the length of the chromosome, the amount of euchromatin deleted, ring stability, presence of monosomic lines and other secondary aneuploid lines and the rate of mosaicism [13-17]. A familial variability was detected for inherited rings, but the phenotype is less severe than in sporadic rings $[3,5,18]$.

A special condition called "ring syndrome" is characterized by severe growth retardation, but with a pseudo-normal phenotype (without major anomalies and with only a few minor dysmorphic features) [19]. In the largest study on ring chromosomes, Kosztolányi [5] showed that ring syndrome has a frequency of $20.0 \%$. A plausible hypothesis for this syndrome's relatively mild phenotype is the presence of an apparently complete ring chromosome without loss of genetic material, and thus, the phenotype does not depend on an implicated autosome. The mechanism proposed for growth retardation was ring instability that leads to cellular death $[5,20]$.

A special mechanism was proposed for ring chromosomes that involve a large chromosome. In this case, a "dynamic mosaicism" was generated by sister chromatide exchanges that produce interlocked rings, broken rings, double rings or other anomalies $[11,21]$.

\section{MATERIALS AND METHODS}

We collected the cases from three different laboratories in Romania, namely the Cytogenetic Laboratory of "Grigore T. Popa" University of Medicine and Pharmacy, Iasi, the Cytogenetic Laboratory of "Prof. Dr. Alfred Rusescu" National Institute for Mother and Child Care, Bucharest, and a private Cytogenetic
Laboratory from Timisoara (Table 1). Our study was based on conventional banding cytogenetic and fluorescence in situ hybridization (FISH) analyses. In all cases, the chromosomal analysis was performed on a short time T lymphocyte culture stimulated by phytohemagglutinin. The chromosomes were G-banded using trypsin and Giemsa solution according to standard techniques. Conventional banding cytogenetic analysis was performed both for the proband and his/ her parents in all cases.

The FISH protocol was only applied for the cases with ring chromosome 18 . In these cases, FISH was performed using chromosome 18-specific direct-labeled probes: telomeric probes for chromosome 18 (Aquarius ${ }^{\circledR}$; Cytocell Technologies Ltd., Cambridge, Cambridgeshire, UK) and Aquarius ${ }^{\circledR}$ Whole Chromosome Painting Probes (Cytocell Technologies Ltd.). The results of conventional banding cytogenetic analysis and FISH were elaborated in accordance with the guidelines of the International System of Human Cytogenetic Nomenclature (2009) (ISCN) [22].

\section{RESULTS}

Case 1. A girl, born at full-term, weight 1550 $\mathrm{g}$, length $38 \mathrm{~cm}$ and head circumference (OFC) 28 $\mathrm{cm}$. Postnatal development showed severe developmental delay, hyperactivity, aggression, mewing cry in the neonatal period. Clinical examination at 3 years of age revealed short stature [ -2.8 standard deviation (SD), microcephaly (OFC $-4.3 \mathrm{SD}$ ), dysmorphic face (triangular face, mild facial asymmetry, hypertelorism, abnormal, low set, asymmetric ears) (Figure 1). She presented severe mental retardation (IQ 40) and challenging behavior. Echocardiography showed: subaortic ventricular septal defect (VSD), tri-cuspid insufficiency, foramen ovale apertum with-

Table 1. Number of ring cases reported to overall number of karyotypes at the three Romanian laboratories.

\begin{tabular}{|l|c|c|c|}
\hline Laboratory & $\begin{array}{c}\text { Number of } \\
\text { karyotype }\end{array}$ & $\begin{array}{c}\text { Number of } \\
\text { Autosome Rings }\end{array}$ & Time \\
\hline $\begin{array}{l}\text { Cytogenetic Laboratory “Grigori T. Popa”, } \\
\text { University of Medicine and Pharmacy, Iasi }\end{array}$ & 5051 & 3 & $1965-2011$ \\
\hline $\begin{array}{l}\text { Cytogenetic Laboratory, "Professor Dr. Alfred Rusescu”, } \\
\text { Institute for Mother and Child Care, Bucharest }\end{array}$ & 2277 & 3 & $1986-2011$ \\
\hline Cytogenetic Laboratory, "Dr. Gug”, Timisoara & 3173 & 0 & $2002-2011$ \\
\hline Total & 10501 & 6 & \\
\hline
\end{tabular}



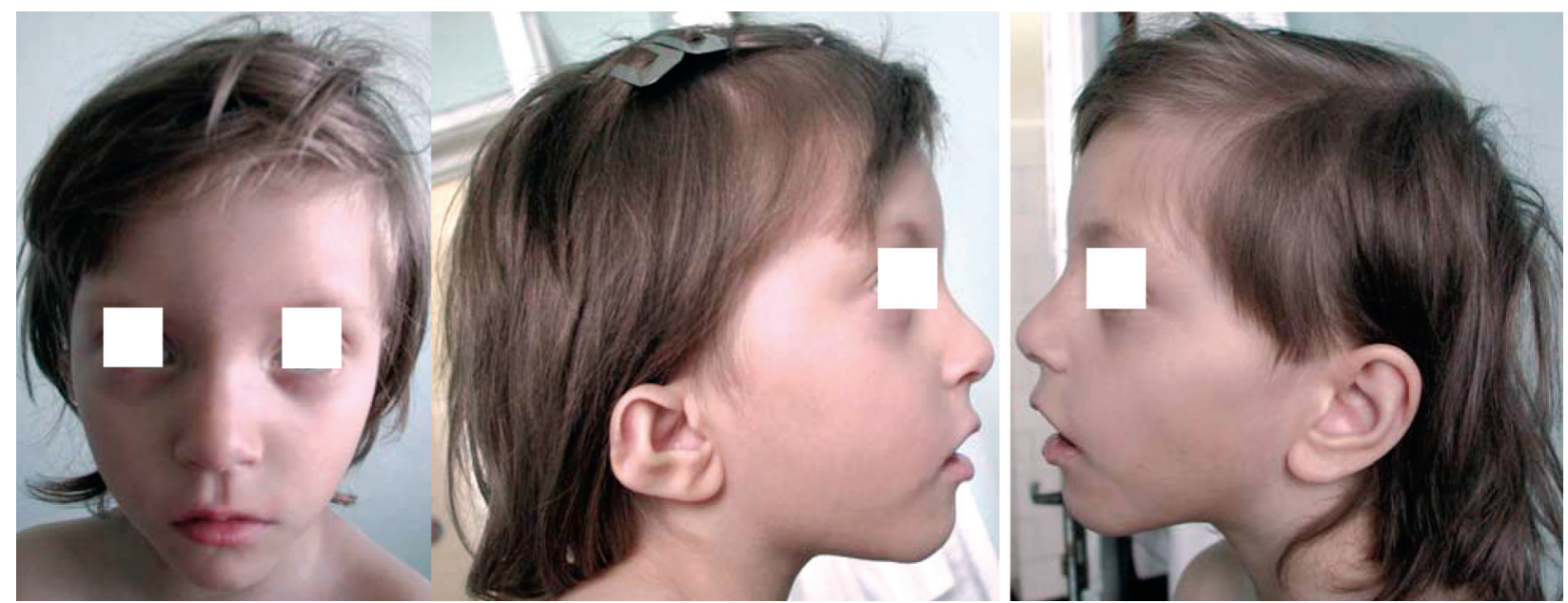

Figure 1. The phenotype of case 1: a) facial asymmetry; b) microtia; c) low set, normal conformed ear.

out pulmonary hypertension. Renal ultrasound was normal. The clinical diagnostic supposition was Cri du Chat syndrome. Blood karyotype: $\operatorname{mos} 46, X X, r(5)$ (p14q35)[80]/45,XX,-5[8]/47,XX,r(5)(p14q35),r(5) (p14q35)[3] (Figure 2). The karyotype of both parents was normal.

Case 2. A boy, born at full-term, weight 1600 $\mathrm{g}$, length $42 \mathrm{~cm}$ and OFC $28 \mathrm{~cm}$ (severe intrauterine

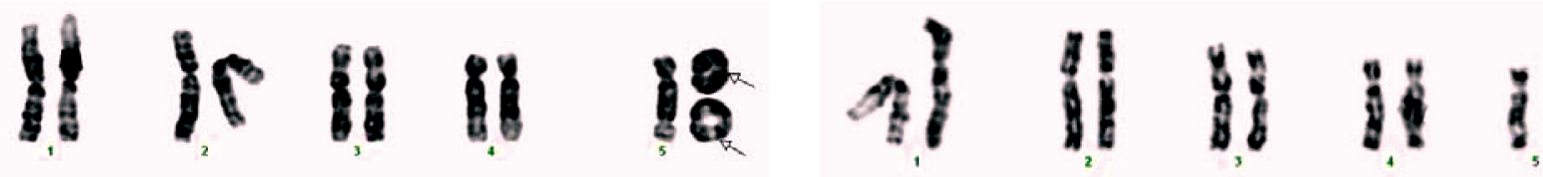

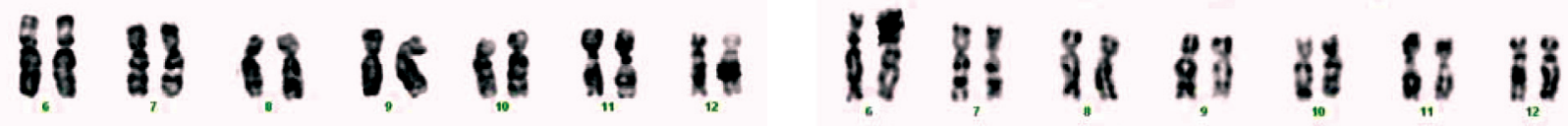

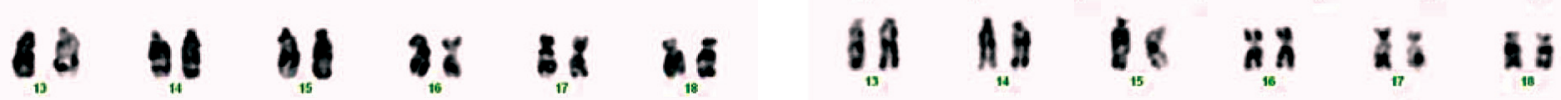

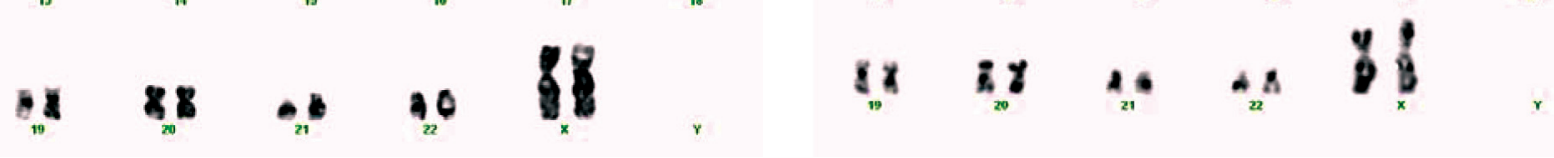 47,XX,r(5)(p14q35), r(5)(p14q35) $45, X X,-5$}

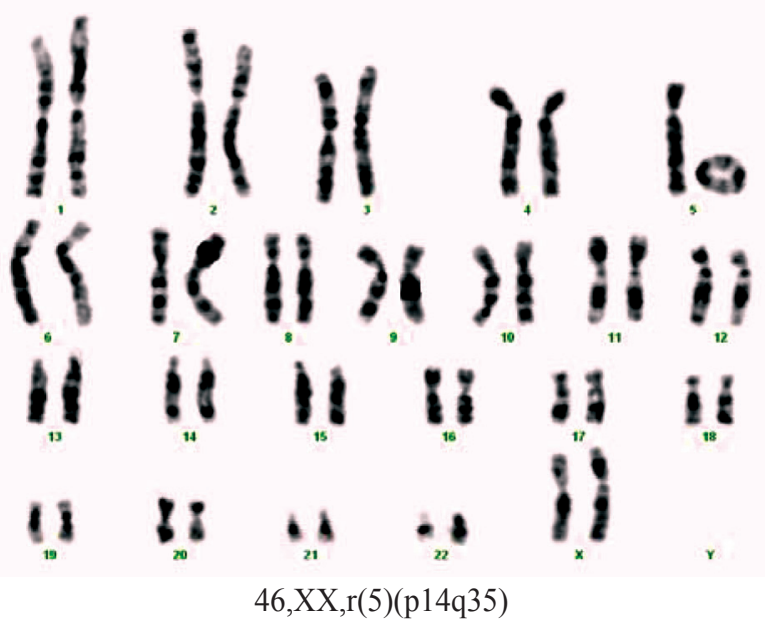

Figure 2. Karyotype of case 1. 

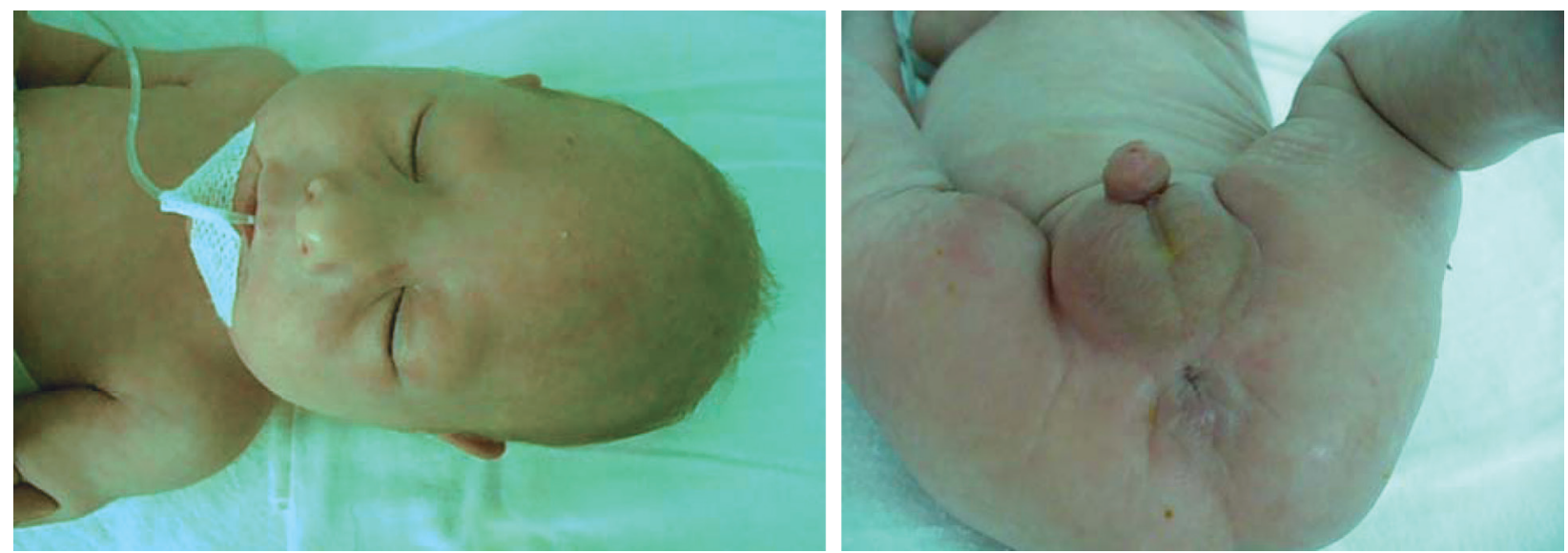

Figure 3. Case 2: a) the facial dysmorphism; b) the aspect of urogenital region.

growth retardation). The patient was the first child of a young, apparently healthy and unrelated couple. Clinical exam at age of 2 days showed: growth retardation, microcephaly with doli-cocephaly, hypertelorism, epicanthic folds, small nose with anteverted nostrils, broad and prominent nasal bridge, ogival palatine vault, long philtrum, micrognathia, big, low set ears with posterior rotation, short neck, micropenis, anteriorly displaced anus and deep sacral dimple (Figure 3). Hematological investigations, liver and renal
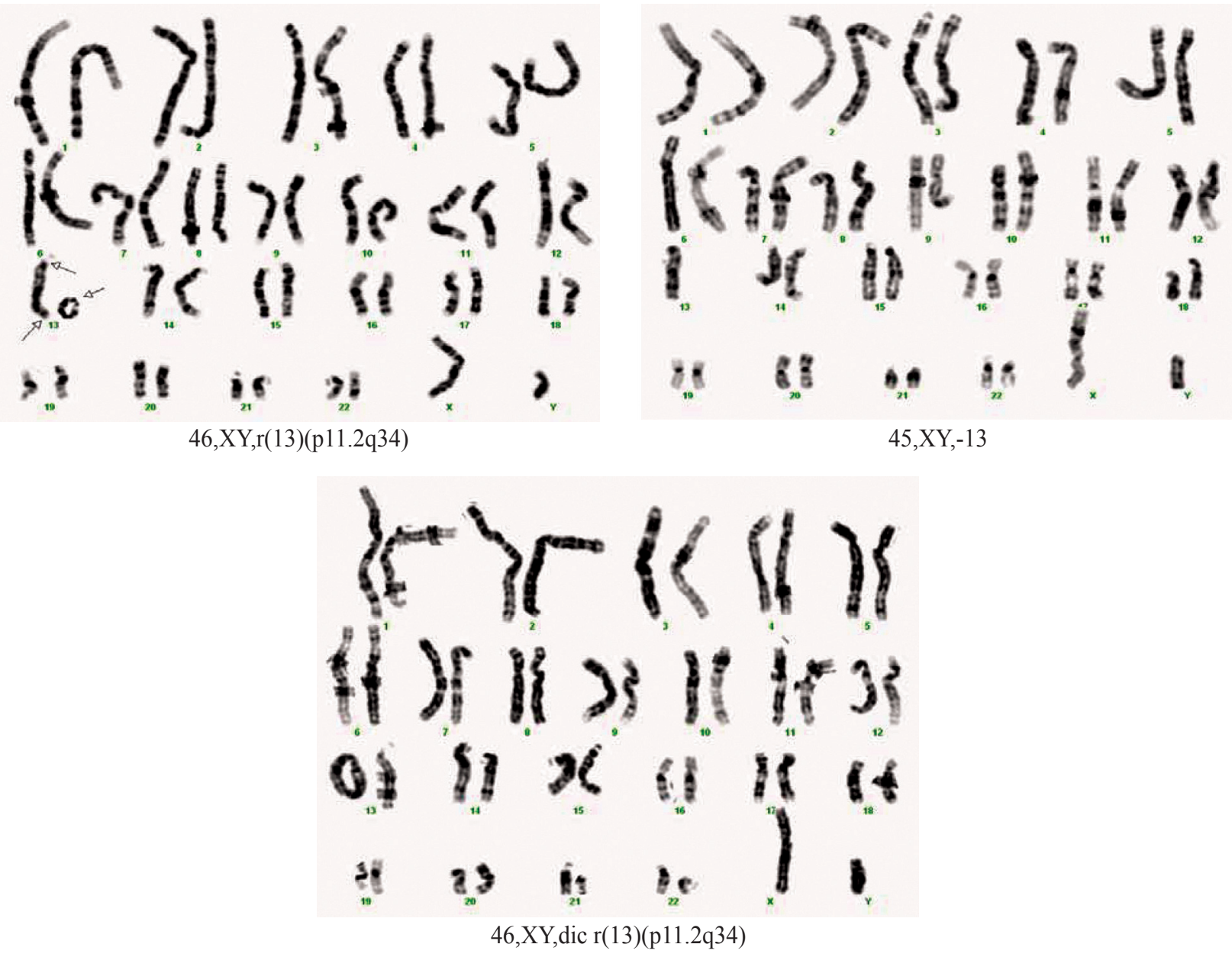

Figure 4. Karyotype of case 2. 

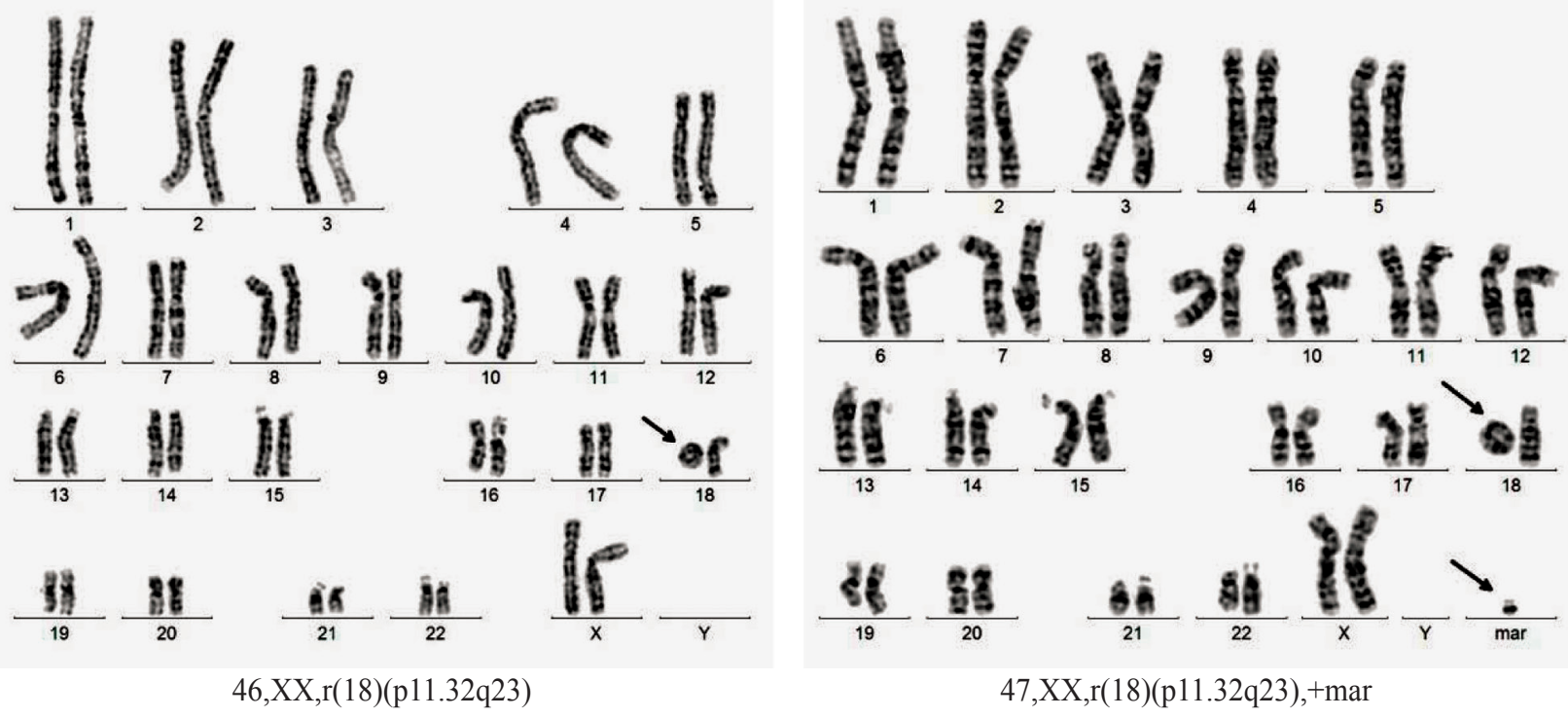

Figure 5. Karyotype of case 3.

function tests were normal. Cardiac ultrasonography attested patent ductus arteriosus (PDA), foramen ovale apertum and diastolic dysfunction of the left ventricle. The postnatal evolution was marked by severe growth retardation and the child died at the age of 2 months. Blood karyotype: mos 46,XY,r(13)(p11.2q34) [51]/45,XY,-13[12]/46,XY,dic r(13)(p11.2q34)[1] (Figure 4). The karyotype of both parents was normal.

Case 3. A girl born at full term weighing $3400 \mathrm{~g}$ and length of $54 \mathrm{~cm}$. She is the second child of a couple apparently healthy and unrelated (mother aged 32 years and father aged 42 years at time of conception). Clinical examination at the age of 13 years and 7 months revealed: weight $=43.5 \mathrm{~kg}$, height $=152$ $\mathrm{cm}, \mathrm{OFC}=51.5 \mathrm{~cm}$, dys-morphic features (hypertelorism, facial scar secondary to surgical procedures to correct cleft lip), mental retardation (she doesn't attend a mainstream school). From pathological history we mention: left cleft lip surgically corrected, sensorineural hearing loss, bilateral stenosis of external auditory canals, clubfoot. Cranial magnetic resonance imaging: acquired lesion of corpus callosum. Blood karyotype: mos 46,XX,r(18)(p11.32q23) [43]/47,XX,r(18) (p11.32q23), +mar[7] (figure 5). Blood karyotype of both parents was normal.

For supplementary investigation of the ring chromosome 18, FISH probes for telomeres of chromosome 18 (Aquarius ${ }^{\circledR}$; Cytocell Technologies Ltd.) were applied. The results of the investigation showed the presence of telomeres for the normal chromosome 18 only (green signal) and absence of the telomeres for the ring chromosome 18 (Figure 6).
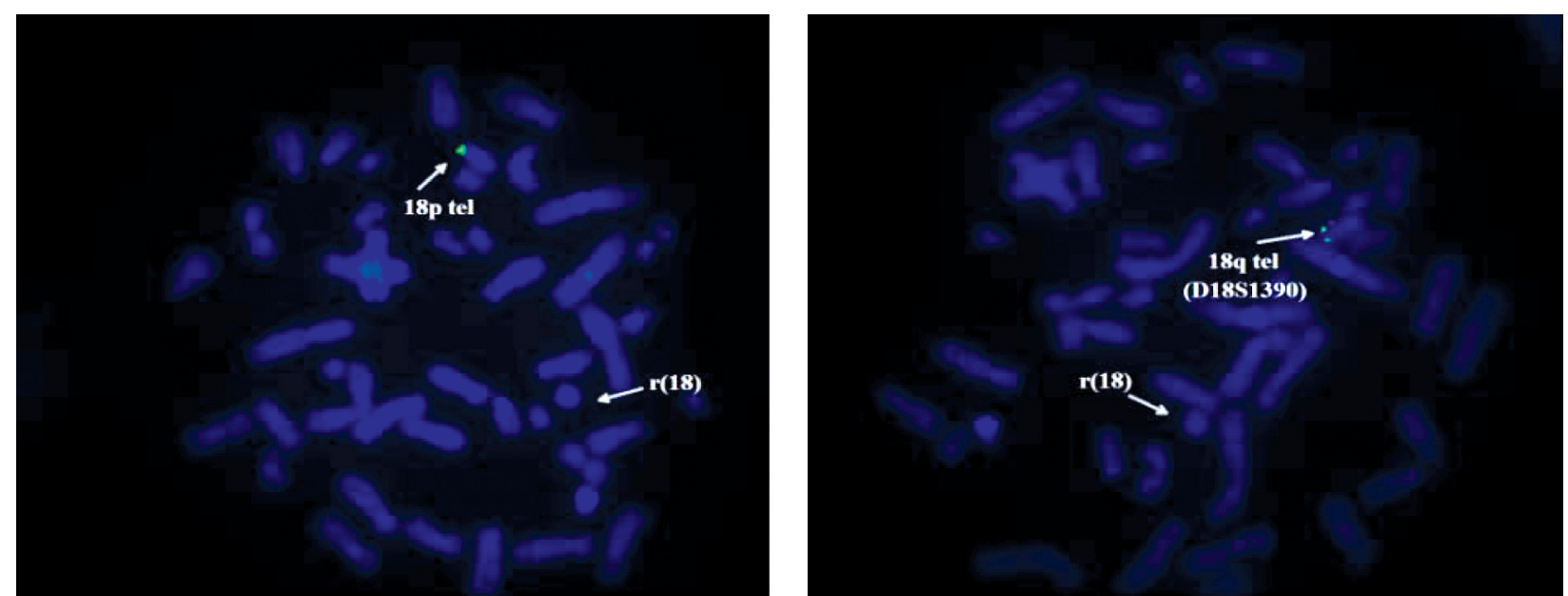

Figure 6. The FISH analysis of case 3: a) probe for telomere 18p; b) probe for telomere 18q. The absence of green signals on the the ring chromosome 18; the genetic material of the marker does not belong to chromosome 18 . 


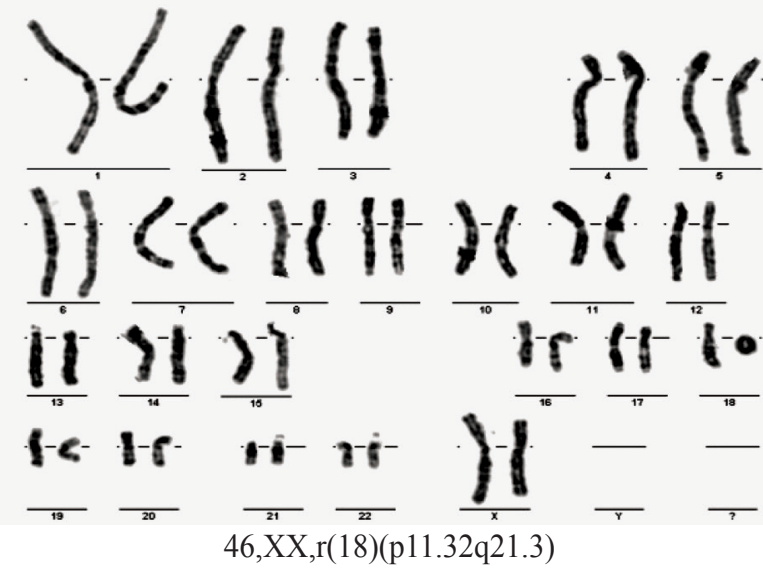

Figure 7. Karyotype of case 4.

Case 4. A girl, born at full-term, weight $3000 \mathrm{~g}$, length $50 \mathrm{~cm}$ and head circumference $34 \mathrm{~cm}$. Her parents were young, apparently healthy and unrelated. Clinical examination at the age of 2 showed: weight $=$ $8000 \mathrm{~g}$, height $=84 \mathrm{~cm}, \mathrm{OFC}=46 \mathrm{~cm}$, dysmorphic features (hypertelorism, narrow ear canals, micrognathia), club foot varus, impaired hearing, developmental delay. Abdominal ultrasound revealed horseshoe kidneys. Blood karyotype 46,XX,r(18) (p11.32q21.3) (Figure 7). Blood karyotype of both parents was normal.

To investigate the breakpoints on ring chromosome 18, we applied FISH probes for both subtelomeres 18p (D18S552 - red) and 18q (D18S1390 - green) of chromosome 18 (Aquarius $\AA$; Cytocell Technologies Ltd.). The results of the investigation showed the presence of subtelo-meric FISH signals only on the normal chromosome 18 [red signal for 18 short arm (p) and green signal for 18 long arm (q)] and the absence of fluorescent signals on ring chromosome 18 (Figure 8). We also used FISH analysis with Aquarius ${ }^{\circledR}$ Whole Chromosome Painting Probes (Cytocell Technologies Ltd.) marked with a green fluoro-phore for chromosome 18; this attested the origin of the ring chromosome (Figure 9).

Case 5. A boy, born at full-term, weight 3500 g, length $52 \mathrm{~cm}$ and OFC $35 \mathrm{~cm}$. His parents were young and non consanguineous. Clinical examination at age of 2 months showed: weight $=4940 \mathrm{~g}$, height $=53 \mathrm{~cm}$, dysmorphic fea-tures (short neck, narrow bitemporal diameter, preauricular pits, large ears, bulbous nose, anteverted nostrils, long philtrum, macrostomia, thin upper lip, short lingual fren-ula), hypospadias. Echocardiography discovered VSD and PDA. Blood karyotype 46,XY,r(18)(p11.32q23) (Figure 10). Blood karyotype of both parents was normal.

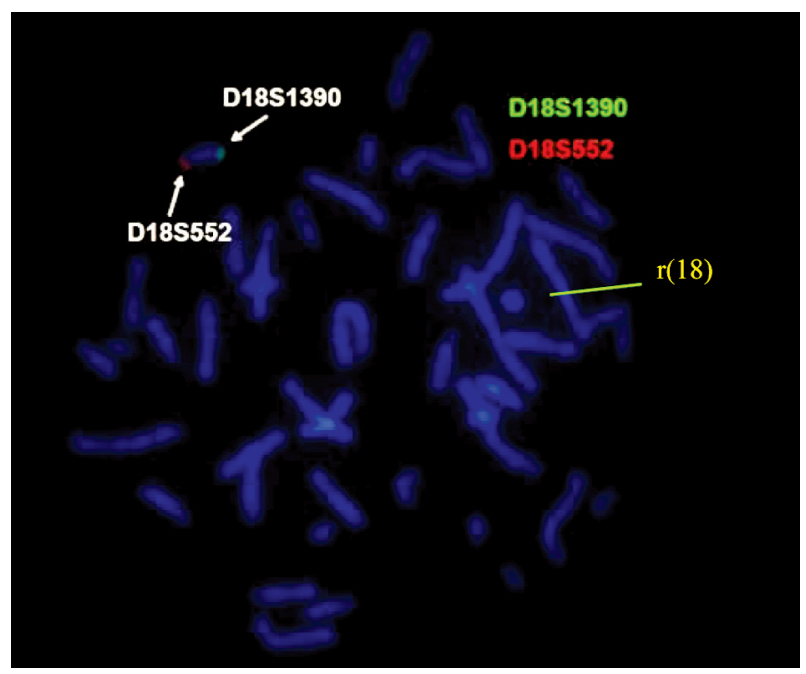

Figure 8. The FISH analysis with probes for subtelo-meres 18p (D18S552 - red) and 18q (D18S1390 - green) in case 4.

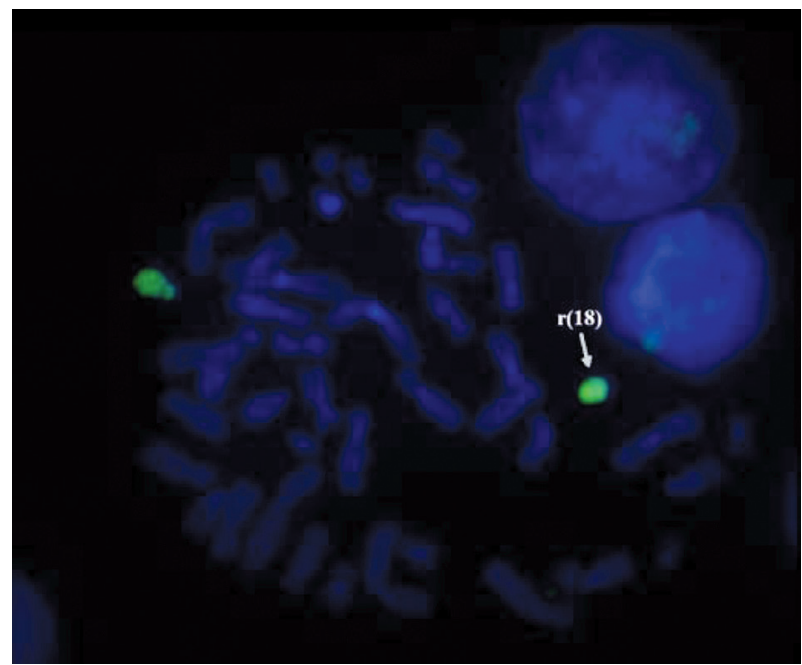

Figure 9. The FISH analysis with Aquarius ${ }^{\circledR}$ Whole Chromosome Painting Probes (Cytocell Technologies Ltd.) using a green fluorophore for chromosome 18 in case 4 .
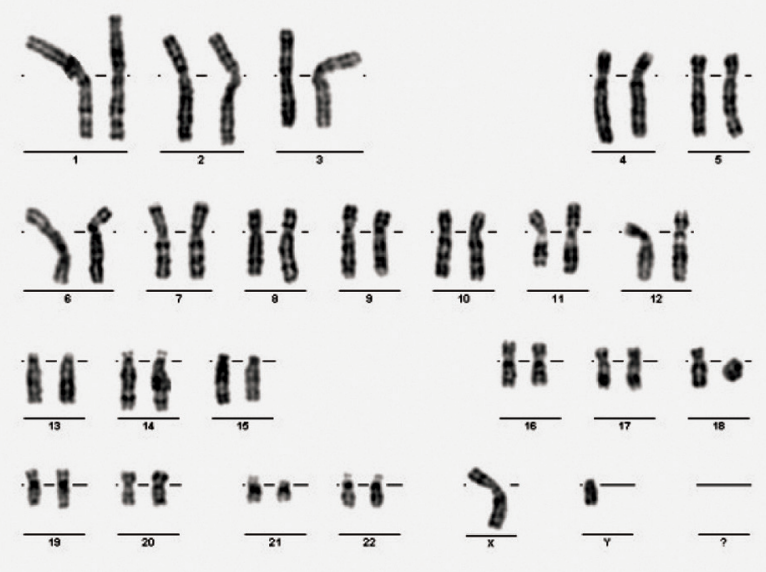

46,XY,r(18)(p11.32q23)

Figure 10. Karyotype of case 5. 


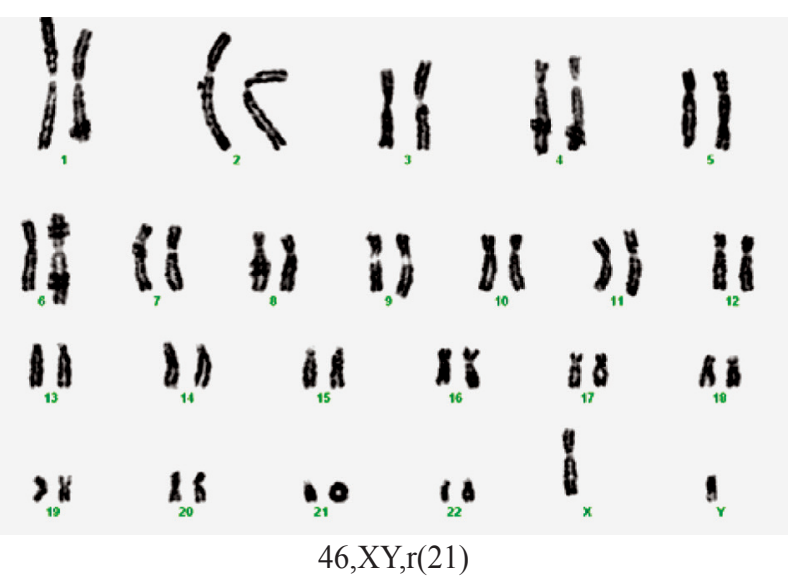

Figure 11. Karyotype of case 6.

Case 6. A boy, born prematurely with a weight of $2000 \mathrm{~g}$, length $48 \mathrm{~cm}$, and an Apgar score of 7. Obstetrical history indicated an imminent abortion two months after conception. Clinical examination at 2 months old revealed: microcephaly, dysmorphic craniofacial features with high forehead, down-slanted palpebral fissure, low set ears, prominent antihelix, flattened helix, large concha, micro-gnathia, microstoma, cleft palate. The patient also presented muscular hypertonia, systolic heart murmur, umbilical and inguinal bilateral hernia, undescended right testis, right simian crease, left Sydney crease. The patient's evolution did not improve and he died at 3 months. The postmortem examination revealed a large septal atrial defect (for this old case, the echocardiography was unavailable). Karyotype 46,XY,r(21) (Figure 11). Blood karyotype of both parents was normal.

\section{DISCUSSION}

We synthesized the results of conventional banding cytogenetic analyses using these criteria: number of chromosomes of each cell, presence of one monocentric ring chromosome, absence of ring chromosome and presence of some derivative chromosomes resulting from mitotic instability of the ring (two monocentric rings, dicentric ring), normal diploid cell (Table 2).

Ring chromosome is an unbalanced abnormality. According to the number of rings there are two situations. In the first situation, one chromosome is replaced by the ring and this generates deletion/ monosomy of implicated genes. In the second situation, a supernumerary ring is present and it generates a duplication/trisomy of that part of the chromosome implicated in ring formation in association with partial monosomy [8]. For this reason the phenotype of the patient depends on the presence of secondary chromosome lines and the percentage of mosaicism. Also, a rare situation was described when one normal chromosome was replaced by two rings derived from the same chromosome. The first case was reported by Miller et al. [23] in 2003.

A condition similar to the second situation was identified for case 1 . In this case, 91 cells were examined and three cell lines were found. The resolution of the karyotype was approximately 400 bands per haploid set. Eighty cells (88.0\%) had a ring chromosome with apparent breakpoints in the short arm at band $5 \mathrm{p} 14$ and in the long arm at band 5q35. Eight cells $(8.8 \%)$ had the entire chromosome 5 missing, and three cells (3.29\%) had two 5 ring chromosomes and a normal 5 chromosome in the same cell. In case 1, lack of normal diploid line was an argument for meiotic origin. It is very likely that the most frequent line (for those with one ring) is the first one and the others are the expression of mitotic instability of the ring. The monosomic line could be the result of an

Table 2. Results of conventional banding cytogenetic analysis.

\begin{tabular}{|l|c|c|c|c|c|c|}
\hline Number & $\begin{array}{c}\text { One Ring } \\
\text { Line }\end{array}$ & $\begin{array}{c}\text { Monosomy } \\
\text { Line }\end{array}$ & $\begin{array}{c}\text { Double-Size } \\
\text { Ring }\end{array}$ & $\begin{array}{c}\text { Normal } \\
\text { Line }\end{array}$ & Marker & $\begin{array}{c}\text { Two Ring } \\
\text { Lines }\end{array}$ \\
\hline Case $1(\%)$ & $+(80 / 91)(88.0 \%)$ & $+(8 / 91)(8.8 \%)$ & - & - & - & $+(3 / 91)(3.2 \%)$ \\
\hline Case 2 & $+(51 / 64)$ & $+(12 / 64)$ & $+(1 / 64)$ & - & - & - \\
\hline Case 3 & $+(43 / 50)$ & - & - & - & $+(7 / 50)$ & - \\
\hline Case 4 & $++^{\mathrm{a}}$ & - & - & - & - & - \\
\hline Case 5 & + & - & - & - & - & - \\
\hline Case 6 & + & - & - & - & - & - \\
\hline
\end{tabular}

${ }^{\text {a }}$ Confirmed by FISH. 
anaphase lag in mitosis of cell with ring chromosome 5. But the most likely mechanism is the chromatid non disjunction that explains the formation of secondary cellular lines: with monosomy 5 and with two ring chromosome 5 .

The patient's phenotype was suggestive for Cridu-Chat syndrome. Because three different cellular lines were identified for this case, we compared the clinical signs specific for each of them if they appeared as singular abnormalities and clinical features observed for our patient (Table 3). The patient presented mild facial asymmetry and a unilateral ear abnormality (malformed, small, low set right ear). These features represent minimal diagnostic criteria for oculo-auriculo-vertebral spectrum (OAVS). The main feature that suggested the diagnosis was microtia. Isolated microtia is considered the mildest form of OAVS [25]. Tasse et al. [26] proposed the following diagnosis criteria: hemifacial microsomia with preauricular tags or microtia (with or without preauricular skin tags). Marked facial asymmetry is present in only $20.0 \%$ of cases, but the overall frequency is about $65.0 \%$. It becomes more apparent by the age of 4 . Our patient was examined at the age of 3 and we expect the facial asymmetry to be emphasized in the future. The association between $5 p$ monosomy and OAVS has been described before and some authors suggested there are some genes on $5 p$ implicated in OAVS pathogeny [27-30].

Heart defects have been reported in OAVS in $5.0-58.0 \%$ cases in different studies. Digilio et al. [31] communicated a frequency for VSD and PDA (these defects were also present in our patient) of $6 / 87$, respectively of $1 / 87$, but in that study, the patients with documented chromosomal abnormalities were excluded. These types of heart defects also appear in Cri-du-Chat syndrome and they have been frequently associated with deletions of the distal part of $5 q$ and in rings with 5q35-5qter deletions [32].

Lorentz et al. [33] made a classification of cases with ring chromosome 13. They identified four categories of chromosomal anomalies named A-D, each of them having specific deletion: A was a mosaic partial monosomy 13q, B was non mosaic rearrangements such as rings or deletions that lead to a net deletion for distal 13q, C was mosaicism for a distal $13 \mathrm{q}$ deletion and complete mono-somy 13 and $\mathrm{D}$ was complex chromosome rearrangements that result in mosaicism for partial duplications and partial dele- tions of chromosome 13 [33]. Previously, we showed that our case belongs to group C [34]. The presence of a dicentric ring chromosome 13 in the karyotype of our patient can be explained by a sister chromatid exchange of the monocentric ring after replication. In our case, we consider that dicentric ring chromosome 13 has a Tai Chi configuration (an inverted mirror image of the two halves of the double-sized ring chromosome 13) in correlation with the mechanism proposed by Hoo et al. [35].

For cases 1 and 2, the presence of a monosomic line as a part of a "dynamic mosaicism" partially influences the phenotype, especially growth (both patients have growth retardation). Kosztolányi [5] postulate that the ring behavior and the structure are responsible for growth failure.

For case 3, the GTG-banded karyotype showed two cell lines, both with 18 ring chromosome. The less frequent line (7/50 metaphases) has a marker chromosome unidentified by conventional banding cytogenetic analysis or FISH. The marker chromosome looks like an inverted duplicated chromosome of an acrocentric but it was not checked by nuclear organizing region (NOR) banding. Over $70.0 \%$ of small marker chromosomes are de novo (like our case) and over $70.0 \%$ of the overall cases are derived from acrocentric chromosomes. The phenotype was normal in $74.0 \%$ of individuals with a de novo small supernumerary marker chromosome (sSMC). On the other hand, the frequency of marker chromosomes among different clinical situations varies from 7.0 to $28.0 \%$ and the incidence of marker chromosomes in mentally retarded patients is only $0.288 \%$. Other phenomena that limited the phenotypic importance of marker chromosomes were the decrease of percentage of cells with marker chromosomes during lifetime. Thus, in our case, it is hard to say if some features such as mental retardation, were the result of a deleted region on chromosome 18 or was influenced by the presence of a marker chromosome [36]. Fluorescence in situ hybridization analysis with telomeric probes for both arms of chromosome 18 demonstrated the presence of a telomeric region just for the normal chromosome and absence for the ring chromosome.

For cases 4 and 5, the GTG-banded karyotype revealed a homogeneous abnormality: 18 ring chromosome. In case 4 , by using Aquarius ${ }^{\circledR}$ Whole Chromosome Painting Probes (Cytocell Technologies Ltd.) for chromosome 18, the origin of the ring 
Table 3. Comparison of phenotypes in $5 p$ monosomy, $5 p$ trisomy, $5 q$ trisomy and clinical features of case 1 [24]. ([+]: present; [-]: absent.)

\begin{tabular}{|c|c|c|c|c|}
\hline Clinical Feature & 5p monosomy & 5p Trisomy & 5q Trisomy & Case 1 \\
\hline Low birth weight & {$[+]$} & {$[-]$} & {$[+]$} & {$[+]$} \\
\hline Early death & {$[-]$} & {$[+]$} & {$[-]$} & {$[-]$} \\
\hline Cat-like cry & {$[+]$} & {$[-]$} & {$[-]$} & {$[+]$} \\
\hline Microcephaly & {$[+]$} & {$[-]$} & {$[+]$} & {$[+]$} \\
\hline Macrodolichocephaly & {$[-]$} & {$[+]$} & {$[-]$} & {$[-]$} \\
\hline Hydrocephalus & {$[-]$} & {$[+]$} & {$[-]$} & {$[-]$} \\
\hline Round face & {$[+]$} & {$[-]$} & {$[-]$} & {$[-]$} \\
\hline Abnormal skull shape & {$[-]$} & {$[-]$} & {$[+]$} & {$[+]$} \\
\hline Micrognathia & {$[+]$} & {$[-]$} & {$[+]$} & {$[-]$} \\
\hline Downward-slanting palpebral fissures & {$[+]$} & {$[-]$} & {$[+]$} & {$[-]$} \\
\hline Upward-slanting palpebral fissures & {$[-]$} & {$[+]$} & {$[-]$} & {$[-]$} \\
\hline Hypertelorism & {$[+]$} & {$[+]$} & {$[-]$} & {$[-]$} \\
\hline Epicanthic fold & {$[+]$} & {$[+]$} & {$[+]$} & {$[-]$} \\
\hline Strabismus & {$[+]$} & {$[-]$} & {$[+]$} & {$[-]$} \\
\hline Bulbous nose & {$[-]$} & {$[+]$} & {$[+]$} & {$[-]$} \\
\hline Broad nose bridge & {$[+]$} & {$[-]$} & {$[+]$} & {$[-]$} \\
\hline Low set ears & {$[+]$} & {$[+]$} & {$[+]$} & {$[+]$} \\
\hline Posteriorly rotated ears & {$[-]$} & {$[-]$} & {$[+]$} & {$[+]$} \\
\hline Preauricular tags & {$[+]$} & {$[-]$} & {$[-]$} & {$[-]$} \\
\hline Down-turned corners of the mouth & {$[+]$} & {$[-]$} & {$[-]$} & {$[-]$} \\
\hline Narrow, high arched palate & {$[+]$} & {$[-]$} & {$[-]$} & {$[+]$} \\
\hline Cleft palate & {$[-]$} & {$[-]$} & {$[+]$} & {$[-]$} \\
\hline Transverse flexion creases & {$[+]$} & {$[-]$} & {$[-]$} & {$[-]$} \\
\hline Clinodactyly & {$[+]$} & {$[+]$} & {$[+]$} & {$[+]$} \\
\hline Brachydactyly & {$[+]$} & {$[-]$} & {$[+]$} & {$[-]$} \\
\hline Cerebral malformations & {$[-]$} & {$[+]$} & {$[-]$} & {$[-]$} \\
\hline Congenital hearth defect & {$[+]$} & {$[+]$} & {$[+]$} & {$[+]$} \\
\hline Lung malformations & {$[-]$} & {$[-]$} & {$[+]$} & {$[-]$} \\
\hline Gut malformations & {$[-]$} & {$[+]$} & {$[-]$} & {$[-]$} \\
\hline Kidney malformations & {$[-]$} & {$[+]$} & {$[+]$} & {$[-]$} \\
\hline Limb malformation & {$[-]$} & {$[-]$} & {$[+]$} & {$[-]$} \\
\hline Club foot & {$[+]$} & {$[+]$} & {$[-]$} & {$[-]$} \\
\hline Flat arches of feet & {$[+]$} & {$[-]$} & {$[-]$} & {$[-]$} \\
\hline Anteriorly placed anus & {$[-]$} & {$[+]$} & {$[-]$} & {$[-]$} \\
\hline Feeding difficulty & {$[+]$} & {$[-]$} & {$[-]$} & {$[-]$} \\
\hline Recurrent infections & {$[+]$} & {$[+]$} & {$[-]$} & {$[-]$} \\
\hline Hypotonia & {$[+]$} & {$[-]$} & {$[-]$} & {$[+]$} \\
\hline Seizures & {$[+]$} & {$[+]$} & {$[-]$} & {$[-]$} \\
\hline Psychomotor retardation & {$[+]$} & {$[+]$} & {$[+]$} & {$[+]$} \\
\hline Lack of speech & {$[-]$} & {$[-]$} & {$[+]$} & {$[-]$} \\
\hline Schizophrenia & {$[-]$} & {$[-]$} & {$[+]$} & {$[-]$} \\
\hline Myelodysplastic syndrome & {$[-]$} & {$[-]$} & {$[+]$} & {$[-]$} \\
\hline Acute lymphocyte leukemia & {$[-]$} & {$[-]$} & {$[+]$} & {$[-]$} \\
\hline
\end{tabular}


chromosome was certified. In addition, subtelomeric FISH probes were used for both arms of chromosome 18 and demonstrated the lack of telomere regions for the ring formation. Based on this analysis, a minimum of $220 \mathrm{~kb}$ on terminal 18p and $290 \mathrm{~kb}$ on terminal $18 \mathrm{q}$, were deleted in case 4 .

The phenotype in ring 18 syndrome has some main elements: developmental delay/mental retardation, typical facial features, major abnormalities and immunological problems [37]. The phenotype in all three cases had specific features, especially for $18 \mathrm{q}$ - syndrome, less for $18 \mathrm{p}$ - syndrome. Cleft lip (case 3), narrow or atretic ear canals and hearing loss (cases 3 and 4), foot deformities (cases 3 and 4) are typical signs of $18 \mathrm{q}-$ syndrome. Other features such as cardiac abnormalities (ventricular septal defect and patent ductus arteriosus in case 5) or renal defects (horseshoe kidney in case 4) can be present in both $18 \mathrm{p}$ - and 18q- syndromes. Stankiewicz et al. [6] suggested there were two types of 18 ring chromosomes according to the breakpoints. The first category has the breakpoints at the cen-tromere or nearby and loses the short arm, and the second one has one breakpoint on the long arm and has only a deletion of distal 18q. Our cases with 18 ring chromosome belonged to the second category. In 2007, Feenstra et al. [38] updated the phenotypic map for chromosome $18 \mathrm{q}$ deletions. The authors identified some (various) critical regions for cardinal signs in 18q deletions (Table 4) and some of the clinical features of our cases are in accordance with these areas. The lack of a normal diploid line suggested that the 18 ring chromosome is formed in meiosis.

Ring chromosome 21 was reported to be de novo or inherited. The phenotypes were different: almost normal in familial cases and characterized by mental retardation or developmental delay, short stature, microcephaly, epican-thus, short neck and small ears. According to loss of material or extra material from chromosome 21, three types of 21 ring chromosome were discribed. Clinically, type I is associated with normal development, no malformations, in some cases short stature, infertility, and slightly delayed puberty in boys. The breakpoint is near the end of the $\mathrm{q}$ arm with minimal loss of genetic material [39]. The second type has different features synthesized by de Grouchy and

Table 4. Comparison of main features mapped by Feenstra et al. [38] in our patients related to deleted regions in ring chromosomes.

\begin{tabular}{|c|c|c|c|c|}
\hline Clinical Features & Critical Region & $\begin{array}{c}\text { Case } 3 \\
\mathbf{r}(18)(\mathrm{p} 11.32 \mathrm{q} 23)\end{array}$ & $\begin{array}{c}\text { Case } 4 \\
\mathrm{r}(18)(\mathrm{p} 11.32 \mathrm{q} 21.3)\end{array}$ & $\begin{array}{c}\text { Case 5 } \\
\mathrm{r}(18)(\mathrm{p} 11.32 . q 23)\end{array}$ \\
\hline Microcephaly & $18 \mathrm{q} 21.33$ & - & - & - \\
\hline Short stature & $\begin{array}{c}18 \mathrm{q} 12.1-\mathrm{q} 12.3 \\
18 \mathrm{q} 21.32-\mathrm{q} 21.33 \\
18 \mathrm{q} 22.3-\mathrm{q} 23\end{array}$ & - & - & - \\
\hline $\begin{array}{l}\text { Congenital aural } \\
\text { atresia }\end{array}$ & 18q22.3-qter & $\begin{array}{l}{[+] \text { (bilateral stenosis of }} \\
\text { external auditory canals) }\end{array}$ & {$[+]$ (narrow ear canals) } & - \\
\hline $\begin{array}{l}\text { Cleft palate (with } \\
\text { or without cleft lip) }\end{array}$ & $\begin{array}{c}18 \mathrm{q} 12.1-\mathrm{q} 12.3 \\
18 \mathrm{q} 22.3-\mathrm{q} 23\end{array}$ & {$[+]$ (cleft lip) } & - & - \\
\hline $\begin{array}{l}\text { Mid- and forefoot } \\
\text { deformities }\end{array}$ & $18 \mathrm{q} 22.3-\mathrm{q} 23$ & {$[+]($ club feet $)$} & {$[+]$ (club feet) } & - \\
\hline $\begin{array}{l}\text { White matter } \\
\text { alterations and } \\
\text { delayed myelination }\end{array}$ & $18 \mathrm{q} 23$ & NI & NI & NI \\
\hline Learning difficulties & $\begin{array}{c}\text { proximal to } 18 \mathrm{q} 21.33 \\
\text { distal to } 18 \mathrm{q} 21.33 \\
\text { (mild MR when present) }\end{array}$ & {$[+]$} & {$[+]$} & - \\
\hline $\begin{array}{l}\text { Immunoglobulin A } \\
\text { deficiency }\end{array}$ & distal to $18 \mathrm{q} 21.32$ & NI & NI & NI \\
\hline
\end{tabular}

NI: no information; MR: mental retardation. 
Turleau [40]: hypertonia, proeminent occiput, protruding forehead, down-slanting palpebral fissures, large ears and others such as ocular anomalies, micrognathia, cleft lip or palate, heart defects, inguinal hernias, hypospadias, undescended testes, learning difficulties, defects in the immune system. These features were associated with the loss of region 21q22.3 or parts of this region in the mechanism of ring formation [40]. The third type of 21 ring chromosome shares features with Down's syndrome because these patients have three copies of chromosome 21. It has been suggested as a possible mechanism two breaks on different arms of a 21q isochromosome, followed by fusion in a circular configuration [39]. Considering these features, we concluded that our case belonged to the second category.

In conclusion, ring chromosomes are rare abnormalities, most of the time of de novo origin, presenting a different phenotype according to the loss of genetic material and genetic instability. The karyotype represents the main analysis for detection of ring chromosomes, but other molecular techniques are necessary for complete characterization. Also, parental investigation is required for proper genetic counseling.

\section{REFERENCES}

1. Kosztolányi G. The genetics and clinical characteristics of constitutional ring chromosomes. J Assoc Genet Technol. 2009; 35(2): 44-48.

2. Schinzel, A. Catalogue of Unbalanced Chromosome Aberrations in Man. Berlin: de Gruyter, 1983.

3. Kosztolányi G, Méhes K, Hook EB. Inherited ring chromosomes: an analysis of published cases. Hum Genet. 1991; 87(3): 320-324.

4. Yardin C, Esclaire F, Terro F, Baclet MC, Barthe D, Laroche C. First familial case of ring chromosome 18 and monosomy 18 mosaicism. Am J Med Genet. 2001; 104(3): 257-259.

5. Kosztolányi G. Does "ring syndrome” exist? An analysis of 207 case reports on patients with a ring auto-some. Hum Genet. 1987; 75(2): 174-179.

6. Stankiewicz P, Brozek I, Hélias-Rodzewicz Z, Wierzba J, Pilch J, Bocian E, et al. . Clinical and molec-ular-cytogenetic studies in seven patients with ring chromosome 18. Am J Med Genet. 2001; 101(3):226-239.

7. Battini R, Battaglia A, Bertini V, Cioni G, Parrini $\mathrm{B}$, Rapalini $\mathrm{E}$, et al. Characterization of the phenotype and definition of the deletion in a new patient with ring chromosome 22. Am J Med Genet A. 2004; 130A(2): 196-199.

8. Glass IA, Rauen KA, Chen E, Parkes J, Alberston DG, Pinkel D, et al. Ring chromosome 15: characterization by array CGH. Hum Genet. 2006; 118(5): 611-617.

9. Rossi E, Riegel M, Messa J, Gimelli S, Maraschio P, Ciccone R, et al. Duplications in addition to terminal deletions are present in a proportion of ring chromosomes: clues to the mechanisms of formation. J Med Genet. 2008; 45(3):147-154.

10. Knijnenburg J, van Haeringen A, Hansson $\mathrm{KB}$, Lankester A, Smit MJ, Belfroid RD, et al. Ring chromosome formation as a novel escape mechanism in patients with inverted duplication and terminal deletion. Eur J Hum Genet. 2007; 15(5): 548-555.

11. Gardner RGM, Sutherland GR. Chromosome Abnormalities and Genetic Counseling, 3rd ed. New York: Oxford University Press; 2004.

12. Kellermayer R, Gyarmati J, Czakó M, Tészás A, Masszi G, Ertl T, et al. Mos 46,XX,r(18).ishr(18) (18ptel-, 18qtel-)/46,XX.ish del(18)(18ptel-): an example for successive ring chromosome formation. Am J Med Genet A. 2005; 139A(3): 234-235.

13. Sodré CP, Guilherme RS, Meloni VF, Brunoni D, Juliano Y, Andrade JA, et al. Ring chromosome instability evaluation in six patients with autosomal rings. Genet Mol Res. 2010; 9(1): 134-143.

14. Tümer Z, Harboe TL, Blennow E, Kalscheuer VM, Tommerup N, Brøndum-Nielsen K. Molecular cytogenetic characterization of ring chromosome 15 in three unrelated patients. Am J Med Genet A. 2004; 130A(4): 340-344.

15. Purandare SM, Lee J, Hassed S, Steele MI, Blackett PR, Mulvihill JJ, et al. Ring chromosome 9 [r(9) (p24q34)]: a report of two cases. Am J Med Genet A. 2005; 138A(3): 229-235.

16. Hockner M, Utermann B, Erdel M, Fauth C, Uter-mann G, Kotzot D. Molecular characterization of a de novo ring chromosome 6 in a growth retarded but otherwise healthy woman. Am J Med Genet A. 2008; 146A(7): 925-929.

17. Zollino M, Seminara L, Orteschi D, Gobbi G, Giovannini S, Della Giustina E, et al. The ring 
14 syndrome: clinical and molecular definition. Am J Med Genet A. 2009; 149A(6): 1116-1124.

18. Speevak MD, Smart C, Unwin L, Bell M, Farrell SA. Molecular characterization of an inherited ring (19) demonstrating ring opening. Am J Med Genet A. 2003; 121A(2): 141-145.

19. Pezzolo A, Gimelli G, Cohen A, Lavaggetto A, Romano C, Fogu G, et al. Presence of telomeric and sub-telomeric sequences at the fusion points of ring chromosomes indicates that the ring syndrome is caused by ring instability. Hum Genet. 1993; 92(1): 23-27.

20. Koç A, Karaer K, Ergün MA. A case with a ring chromosome 22. Turk J Pediatr. 2008; 50(2): 193-196.

21. Rivera H, Dominguez MG. Variegated aneuploidy and ring chromosome syndromes overlap. Am J Med Genet A. 2010; 152A(1): 228-229.

22. Shaffer LG, Slovak ML, Campbell LJ. International System of Human Cytogenetic Nomenclature: recommendations of the International Standing Committee on Human Cytogenetic Nomenclature. Basel: Karger AG, 2009.

23. Miller K, Pabst B, Ritter H, Nürnberg P, Siebert $\mathrm{R}$, Schmidtke J, et al. Chromosome 18 replaced by two ring chromosomes of chromosome 18 origin. Hum Genet. 2003; 112(4): 343-347.

24. Schlegel Z, Valent A, Hirsch A. Partial mosaic trisomy 5: a new case report with ocular involvement. J Fr Ophtalmol. 2009; 32(8): 533-539.

25. Gorlin RJ, Cohen MM Jr, Hennekam R. Branchial arch and oral-acral disorders. Syndromes of the Head and Neck, 4th ed. New York: Oxford University Press. 2001: 790-798.

26. Tasse C, Majewski F, Böhringer S, Fischer S, Lüdecke HJ, Gillessen-Kaesbach G, et al. A family with autosomal dominant oculo-auriculo-vertebral spectrum. Clin Dysmorphol. 2007; 16(1): 1-7.

27. Choong YF, Watts P, Little E, Beck L. Goldenhar and cri-du-chat syndromes: a contiguous gene deletion syndrome? J AAPOS. 2003; 7(3): 226-227.

28. Dyggve H, Mikkelsen M. Partial deletion of the short arms of chormosome of the 4-5 group (Denver). Arch Dis Child. 1965; 40(209): 82-85.

29. Ladekarl S. Combination of Goldenhar syndrome with cri-dre-chat syndrome. Acta Ophthalmol (Copenh). 1968; 46(3): 605-610.
30. Neu KW, Friedman JM, Howard-Peebles PN. Hemifacial microsomia in cri du chat (5p-) syndrome. J Craniofac Genet Dev Biol. 1982; 2(4): 295-298.

31. Digilio MC, Calzolari F, Capolino R, Toscano A, Sarkozy A, de Zorzi A, et al. Congenital heart defects in patients with oculo-auriculo-vertebral spectrum (Goldenhar syndrome). Am J Med Genet A. 2008; 146 (14): 1815-1819.

32. Basinko A, Giovannucci Uzielli ML, Scarselli G, Priolo M, Timpani G, et al. Clinical and molecular cyto-genetic studies in ring chromosome 5: Report of a child with congenital abnormalities. Eur J Med Genet. 2012; 55(2): 112-116.

33. Lorentz CP, Jalal SM, Thompson DM, BabovicVuksanovic D. Mosaic r(13) resulting in large deletion of chromosome $13 \mathrm{q}$ in a newborn female with multiple congenital anomalies, Am J Med Genet. 2002; 111(1): 61-67.

34. Gorduza E.V, Bujoran C, Pădurariu L, Grămescu M, Ivanov I, Martiniuc V, et al. Presentation of a new case with a mosaic ring chromosome 13: 46,XY,r(13)(p11.2-q34)/45,XY,-13 and a review of literature. RJRD. 2010; 1(1): 17-23.

35. Hoo JJ, Stein CK. "Zwilling" versus "Tai Chi" configuration of double-sized ring chromosome. Am J Med Genet A. 2007; 143(8): 903-905.

36. Liehr T. 2012. Small supernumerary marker chromosomes. http://www.fish.uniklinikumjena.de/sSMC. html. [accessed 16 July 2012].

37. Lo-Castro A, El-Malhany N, Galasso C, Verrotti A, Nardone AM, Postorivo D, et al. De novo mosaic ring chromosome 18 in a child with mental retardation, epilepsy and immunological problems. Eur J Med Genet. 2011; 54(3): 329-332.

38. Feenstra I, Vissers LELM, Orsel M, van Kessel AG, Brunner HG, Veltman JA, et al. Genotypephenotype mapping of chromosome $18 \mathrm{q}$ deletions by high-resolution array $\mathrm{CGH}$ : an update of the phenotypic map. Am J Med Genet A. 2007; 143A(16): 1858-1867.

39. McGinniss MJ, Kazazian HH, Stetten G, Petersen MB, Boman H, Engel E, et al. Mechanisms of ring chromosome formation in 11 cases of human chromosome 21. Am J Hum Genet. 1992; 50(1): 15-28.

40. de Grouchy J, Turleau C. Syndrome r(21). Clinical Atlas of Human Chromosomes. New York: John Wiley and Sons. 1984: 350-355. 